\title{
MAPEAMENTO DOS CURSOS DE PÓS-GRADUAÇÃO EM ADMINISTRAÇÃO E SUAS RESPECTIVAS LINHAS DE PESQUISAS NO BRASIL
}

\section{MAPPING OF POST-GRADUATION IN ADMINISTRATION AND THEIR LINES OF RESEARCH IN BRAZIL}

Natane de Cassia Leivas de Medeiros

Graduada em Administração pelo Centro Universitário Franciscano

Santa Maria, RS, Brasil

E-mail: natanemedeiros@gmail.com

\section{Flaviani Souto Bolzan Medeiros}

Doutoranda em Administração pela Universidade Federal de Santa Maria

Santa Maria, RS, Brasil

E-mail: flaviani.13@gmail.com

\section{Iliane Colpo}

Mestre em Engenharia de Produção pela Universidade Federal de Santa Maria

Santa Maria, RS, Brasil

E-mail: ilicolpo@gmail.com

\section{Andreas Dittmar Weise}

Doutor em Engenharia Civil pela Universidade Federal de Santa Catarina; Professor permanente do Programa de Pós-graduação em Engenharia de Produção da Universidade Federal de Santa Maria

Santa Maria, RS, Brasil

E-mail: mail@adweise.de

\section{RESUMO}

O presente artigo se propõe a realizar um mapeamento dos cursos de pós-graduação em Administração e suas respectivas linhas de pesquisa no Brasil. Para isso, utilizou-se uma pesquisa bibliográfica e documental quanto aos meios de investigação. A coleta de dados foi realizada com base nos cursos recomendados e reconhecidos pela Coordenação de Aperfeiçoamento de Pessoal de Nível Superior (CAPES). Após esse levantamento, verificou-se o site de cada Instituição de Ensino Superior (IES) para fins de averiguação das linhas de pesquisa adotadas em cada programa ofertado. Os resultados mostram que a região Norte possui forte escassez de cursos de pós-graduação, em contraste com regiões como Sul e Sudeste onde se concentram a maioria dos programas disponíveis atualmente. Além disso, a região Sudeste é responsável por mais de $50 \%$ da oferta de cursos de Doutorado em Administração, possuindo também todos os programas melhores avaliados - com conceito 6 e 7 pela CAPES.

Palavras-chave: Pós-graduação. Ensino e Pesquisa. Administração. Mapeamento. Brasil.

\section{ABSTRACT}

This article proposes to undertake a mapping of postgraduate courses in Administration and its respective research lines in Brazil. For this, we used a bibliographical and documentary research about the research means. Data collection was based on recommended courses and recognized by the Higher Education Personnel (CAPES). Following this survey, it was the site of each Higher Education Institution (IES) for investigative purposes of the research lines adopted in each program offered. The results show that the North has acute shortage of graduate courses, in contrast to regions such as South and Southeast which concentrates most programs currently available. In addition, the southeastern region accounts for over $50 \%$ of supply of Administration Doctoral degree, also having all the best programs evaluated - with concept 6 and 7 - by CAPES.

Keywords: Post-graduation. Learning and research. Administration. Mapping. Brazil. 


\section{INTRODUÇÃO}

A administração é um termo que vem do latim ad, que significa direção, tendência para, e minister subordinação ou obediência - designando a execução de tarefas dos assuntos de um grupo (FULGENCIO, 2007). Contudo, não existe um padrão universalmente aceito que melhor defina esse termo, mas, quando se trata do ambiente de negócios se faz necessário procurar um consenso sobre seu significado (KWASNICKA, 2007).

Deste modo, Griffin (2007) entende a administração como um conjunto de atividades - figurando entre planejamento, tomada de decisão, liderança e controle - voltadas ao uso dos recursos da organização, sejam eles humanos, financeiros, materiais e informações a fim de atingir os propósitos de maneira eficiente e efetiva.

Complementarmente, Santos (2014) afirma que, a administração surgiu no início do século XX como uma ciência que transformaria o modo de gerenciar e supervisionar uma organização. No campo no ensino e pesquisa, o curso de mestrado em Administração oferecido pela Fundação Getúlio Vargas do Rio de Janeiro, em 1967, foi o pioneiro na pós-graduação no Brasil (GUIMARÃES et al., 2009).

Nesse sentido, Cirani, Silva e Campanario (2012) acrescentam que somente na década de 1970 outros cursos de mestrado em Administração foram criados no país, nos Estados de São Paulo, Minas Gerais, Rio de Janeiro, Rio Grande do Sul, Santa Catarina, Paraíba, Rio Grande do Norte e Distrito Federal.

Silva e Carvalho (2007) lembram que, no Brasil os cursos de pós-graduação stricto sensu iniciaram somente em 1960, com a criação, no ano de 1951, da Campanha Nacional de Aperfeiçoamento de Pessoal de Nível Superior, atual Coordenação de Aperfeiçoamento de Pessoal de Nível Superior (CAPES).

Sob esse enfoque, Santos (2003, p. 629) cita que, nos anos de 1960, período de modernização do Brasil, a instalação da pós-graduação ocorreu em um contexto de integração que "implicava a expansão de mercados consumidores nos países periféricos e o fomento dos centros produtores de Ciência \& Tecnologia (países centrais)".

Assim sendo, as pós-graduações stricto sensu, de acordo com o Ministério da Educação (MEC, 2014), referem-se aos programas de mestrado e doutorado aberto a todo candidato diplomado em curso superior que atende aos requisitos publicados no edital de seleção de cada instituição de ensino, onde ao término do curso o referido aluno conseguirá um diploma.

Diante do exposto, este artigo se propõe a realizar um mapeamento dos cursos de pós-graduação em Administração e suas respectivas linhas de pesquisa no Brasil. O presente estudo é relevante considerando a carência de pesquisas em Administração no país. Por isso, investir na produção científica a partir de uma rede de pós-graduação forte pode ser uma condição ideal a fim de aumentar tanto o volume como a qualidade na produção do Brasil na área (GUIMARÃES et al., 2009).

Para tanto, este trabalho está segmentado em cinco seções, incluindo esta introdução. Na seção dois segue o referencial teórico trazendo um breve relato dos cursos de pós-graduação no Brasil e, ainda, discussões acerca do rumo desses cursos no país. Na seção três consta a metodologia adotada com as respectivas etapas da pesquisa. Em seguida, a seção quatro apresenta o mapeamento realizado dos cursos de pós-graduação em Administração no Brasil, bem como o mapeamento das suas linhas de pesquisa, 
acompanhado da distribuição geográfica por linha de pesquisa, e também, uma análise estatística dos dados. A quinta e última seção trás as considerações finais a partir do estudo realizado.

\section{REVISÃO DE LITERATURA}

A revisão de literatura do presente trabalho contempla um breve relato da pós-graduação no Brasil, como também, apresenta algumas discussões envolvendo a questão do rumo da pós-graduação no país.

\section{Breve relato da pós-graduação no Brasil}

A história da pós-graduação no Brasil tem início tardio. O embrião para o nascimento dos programas de pós-graduação foi plantado no princípio da década de 1930, com a proposta de implantar um curso nos moldes europeus, do então diretor do Ministério de Educação e Saúde Francisco Campos. O curso de Direito da Universidade do Rio de Janeiro, a Faculdade Nacional de Filosofia e a Universidade de São Paulo foram os pioneiros na inserção do modelo estabelecido no Estatuto das Universidades Brasileiras (SANTOS, 2003).

Neuenfeldt e Isaia (2008) indicam que apenas no final da década de 1960 iniciaram-se os estudos para implementação e regularização dos cursos de pós-graduação no país. O marco inicial se deu em 11 de julho de 1951 com a Campanha Nacional de Aperfeiçoamento de Pessoal de Nível Superior, atual CAPES, através do decreto 29.741.

Tauchen et al. (2013) relatam que foi a Lei n. 5.540/68 que tornou a pós-graduação institucional. Complementarmente, Santos e Azevedo (2009) acrescentam que a institucionalização decorreu da aprovação do parecer 977 de 3 de dezembro de 1965, pela Câmara de Ensino Superior (CES), do então Conselho Federal de Educação (CFE) e que a finalidade do documento era esclarecer a natureza e os objetivos desse ramo da educação.

A CAPES desde então é o órgão governamental responsável tanto pela determinação dos padrões como também pela forma de avaliação da qualidade dos programas de pós-graduação stricto senso no Brasil tendo como propósito assegurar a expansão e consolidação dos mesmos (MACEDO; RODRIGUES; SILVEIRA, 2011).

Sendo assim, em relação ao sistema de avaliação dos programas, Mello, Crubellate e Rossoni (2010) complementam que esse sistema engloba dois processos no caso a avaliação dos programas de pósgraduação que integram o Sistema Nacional de Pós-graduação (SNPG) e a avaliação das propostas de novos cursos de mestrado e doutorado.

Silva Júnior, Ferreira e Kato (2013) afirmam que a CAPES tem como objetivo a capacitação do pessoal de ensino superior e se constituiu por décadas em um órgão do Estado para o investimento e avaliação dos programas de pós-graduação; porém, a partir de 1997 assumiu a função de agência reguladora da pós-graduação brasileira, justificado pela necessidade de formar pesquisadores e criar um sistema de pósgraduação regulado, flexível e produtivo, focada em orientar e reorientar as pesquisas e a produção de conhecimento.

Souza e Reinert (2012) informam que na década de 1970 associa-se, pela primeira vez na história do Brasil, a ciência e tecnologia ao desenvolvimento econômico, fortalecendo o setor e trazendo consigo mais 
investimentos para o desenvolvimento a longo prazo da pós-graduação. Moraes e Giroldo (2012) relatam que, justamente, no setor de pós-graduação que são desenvolvidos projetos e pesquisas que contribuem para o crescimento social, econômico, científico e tecnológico de um país.

Deste modo, Souza e Reinert (2012) entendem que, para o desenvolvimento científico e tecnológico do país é necessário recurso humano qualificado e a pós-graduação é a base para esta formação. Nesse sentido, Rezende (2010, p. 22) corrobora que, para esse tipo de desenvolvimento no Brasil "é necessário à existência de pessoal altamente qualificado, com mentalidade e experiência em pesquisa". A pesquisa é formalizada principalmente nos programas de pós-graduação (MELLO; CRUBELLATE; ROSSONI, 2010).

Silva Júnior, Ferreira e Kato (2013) reforçam que, os recursos aplicados para a inovação tecnológica e das ciências aplicadas foram orientados por vários instrumentos jurídicos - entre eles: a Lei de Diretrizes e Bases da Educação de 1996, pelas Leis da Inovação Tecnológica e da Parceria Público-Privada - esses instrumentos legalistas ampliam e validam a formação e o trabalho dos professores-pesquisadores nas diversas áreas do conhecimento, em especial, na pós-graduação reorganizando a forma de gestão do trabalho e a relação professor e a CAPES.

Paiva (2006) afirma que desde o início de seu desenvolvimento na década de 1960 até a década de 1990 não havia dúvidas em relação à qualidade e serenidade na condução dos cursos de pós-graduação existentes no Brasil, após esta época, os referidos cursos passam a ser avaliados de forma mais criteriosa.

Maccari et al. (2006) reforçam o exposto ao afirmarem que devido as exigências estabelecidas pela CAPES isso vem forçando as Instituição de Ensino Superior (IES), e seus respectivos programas de pósgraduação, no sentido tanto de planejar como também gerir tais cursos de maneira mais efetiva.

\section{Rumos da pós-graduação no Brasil}

Um indicador dos possíveis rumos da pós-graduação no Brasil é o Plano Nacional de Pós-Graduação PNPG 2011-2020, editado pela CAPES que tem por objetivo a definição das diretrizes, metas e estratégias para o desenvolvimento dos programas e pesquisas em pós-graduação brasileiras. O PNPG 2011-2020 será parte integrante do novo Plano Nacional de Educação.

Na seção de documentos setoriais, do referido PNPG 2011-2020 são trazidas colaborações de professores e pesquisadores acerca dos rumos da pós-graduação no Brasil (CAPES, 2010). Sendo assim, considerando importante refletir a respeito destas contribuições, a seguir citam-se as colaborações identificadas no PNPG 2011-2020.

Os pesquisadores Gazzola e Fenalti (2010) propõe um conjunto de direções e metas para o avanço na pós- graduação, centradas em cinco questões principais:

- Conhecimento e Sociedade: Aproximar o conhecimento da sociedade, a utilização púbica do conhecimento;

- Inovações Curriculares e de Formação: diversidade do currículo dos cursos e compatibilidade com o conhecimento disponível, além de incentivar programas multi e transdisciplinares;

- Consolidação Nacional do parque de pós-graduação: Utilizar indicadores de solidariedade para espalhar os cursos e programas no território, a maioria dos cursos de pós-graduação refletem as formas de economia nacional, concentrados nas grandes cidades e ainda nas regiões sul e sudeste; 
- Definição estratégica de crescimento: criação de centros de excelência em âmbito nacional e internacional; e

- Inserção Internacional: fomentar políticas de atração de pesquisadores, dar condições para a competitividade, implantar consórcios internacionais estratégicos.

O grande desafio para a continuidade do desenvolvimento da pós-graduação brasileira está vinculado a profundas alterações da forma de se organizar as possibilidades de formação e de uma visão política avançada (GAZZOLA; FENALTI, 2010). Já Almeida (2010), em suas considerações, é enfático na eliminação do mestrado acadêmico, defendendo a integração do curso ao nível de doutorado, após o cumprimento de algumas etapas o discente poderia obter o título de mestre enquanto que o mestrado profissional seria mantido.

E acrescenta "a pós-graduação brasileira está diante da armadilha do sucesso: se deu certo até aqui, são grandes os incentivos para a continuidade do mesmo modelo. Penso, entretanto, que isso seria um equívoco. O modelo pode e deve ser mudado" (ALMEIDA, 2010, p. 19). Sendo assim, as direções defendidas por Almeida (2010) são: (1) Revolucionar o mestrado: os programas de pós-graduação acadêmica devem ter como objetivo formar doutores; (2) Aumentar a diversidade do sistema de pós-graduação: alteração da forma de avaliação dos cursos, sendo criado um índice de impacto nacional indicando em âmbito doméstico o efeito do que foi produzido; e (3) Aumentando a internacionalização: aumentar o número de estudantes no exterior, pois essa é uma condição para o desenvolvimento de uma pesquisa inovadora.

Enquanto que, Oliveira e Siqueira (2010, p. 30) propõe a estruturação da pós-graduação focada em:

"[...] dois objetivos principais não conflitantes: valorizar o pensamento humano e social como fator para evolução da sociedade e, em segundo, o uso de tecnologia e inovação para o aperfeiçoamento industrial e agropecuário e melhoria da qualidade de vida e a promoção da saúde do povo."

Schwartzman (2010) relata que o atual modelo criado na década de 1970 cumpriu com seu papel, no entanto, necessita de alteração, reduzindo a centralização, estimular a autonomia, e a identificar as diferenças entre os programas que hoje existem com a mesma denominação. Para que esta mudança seja possível Schwartzman (2010) cita alguns princípios que devem ser seguidos, a saber:

- Restabelecer e reforçar a autonômica universitária na criação de cursos de pós-graduação, sem a necessidade de autorização governamental;

- Criar fundos de recursos específicos para apoio à pesquisa e pós-graduação;

- Incentivar a iniciativa privada, incluir o custo de pessoal e administrativo do setor privado nos fundos específicos de apoio a pesquisa e pós-graduação;

- Cobrar anuidade nos programas de pós-graduação públicos ou privados, especialmente nos cursos de cunho profissional; e

- Eliminar os rankings de cursos da CAPES, os recursos devem ser provenientes dos fundos específicos, dos alunos e da universidade. 
A respeito do novo PGPN 2011-2020, Silva Júnior, Ferreira e Kato (2013) concluem que o programa demonstra o quanto à universidade tornou-se uma linha de continuidade do Estado, uma ferramenta de produção utilizada em benefício do capital financeiro mundial. As categorias que podem ser destacadas no PNPG 2011-2020 são: a avaliação intensificada, o empreendedorismo e a internacionalização da pósgraduação brasileira.

\section{METODOLOGIA}

Gonsalves (2012) explica que a metodologia diz respeito ao estudo dos caminhos seguido para atingir o objetivo definido no trabalho, incluindo aí, os procedimentos escolhidos para tal. Deste modo, no caso do presente estudo quanto aos meios de investigação caracteriza-se como uma pesquisa bibliográfica e documental (VERGARA, 2014). A pesquisa bibliográfica, utilizada na sua primeira etapa deste trabalho, no entendimento de Severino (2007), faz uso de materiais já trabalhados por outros pesquisadores, onde os textos devidamente registrados tornam-se fontes para o tema a ser pesquisado.

Já a pesquisa documental, por sua vez, adotada na segunda etapa desse estudo, é semelhante à pesquisa bibliográfica, a única diferença consiste na natureza das fontes, pois a documental utiliza documentos de primeira mão, ou seja, aqueles que não receberam, ainda, qualquer tipo de análise (GIL, 2012).

A coleta dos dados foi realizada com base nos cursos recomendados e reconhecidos pela CAPES (2014), após esse levantamento, verificou-se o site de cada IES para fins de averiguação das linhas de pesquisa adotadas em cada programa oferecido.

Com estes dados, adaptaram-se as referidas linhas de pesquisa encontradas em cada IES em conformidade com as estabelecidas pela Associação Nacional dos Programas de Pós-Graduação em Administração (ANPAD, 2014). O período de realização desse trabalho compreende os meses de janeiro a novembro do ano de 2014 e seguiu as etapas visualizadas na Figura 1 a seguir.

Figura 1 - Etapas adotadas na pesquisa

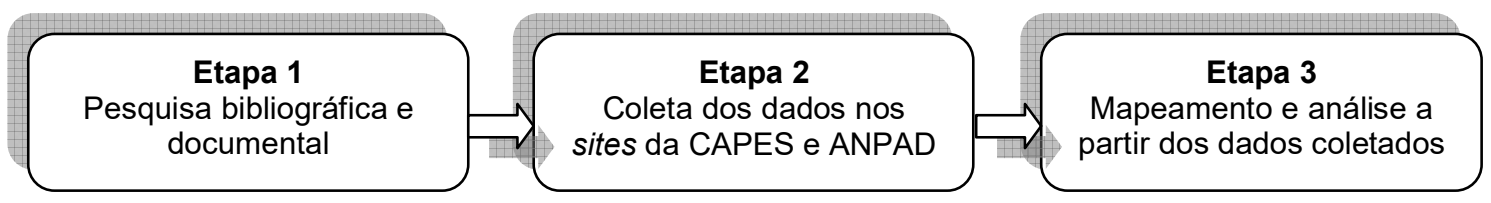

Fonte: Dados da pesquisa (2014).

A partir dos dados coletados foi possível mapear os cursos de pós-graduação em Administração ofertados no Brasil até o presente momento por distribuição geográfica e linhas de pesquisa. Como também, realizou-se uma análise estatística dos dados, apontando à média e desvio padrão das linhas de pesquisa dos referidos cursos e, ainda, a matriz de correlação dos programas e suas linhas. Salienta-se que, os dados coletados foram organizados com o auxílio do software Microsoft Office Excel ${ }^{\circledR}$. 


\section{MAPEAMENTO DA PÓS-GRADUAÇÃO EM ADMINISTRAÇÃO NO BRASIL}

No Brasil, até o presente momento, existem 80 programas de pós-graduação em Administração ofertado por instituições públicas e privadas que são recomendados e reconhecidos pela CAPES (2014). Estes programas encontram-se divididos em Mestrado Acadêmico com 60 opções de cursos, Mestrado Profissional com 30 opções e Doutorado com 37 cursos ofertados. A Figura 2 apresenta a distribuição geográfica desses cursos no país.

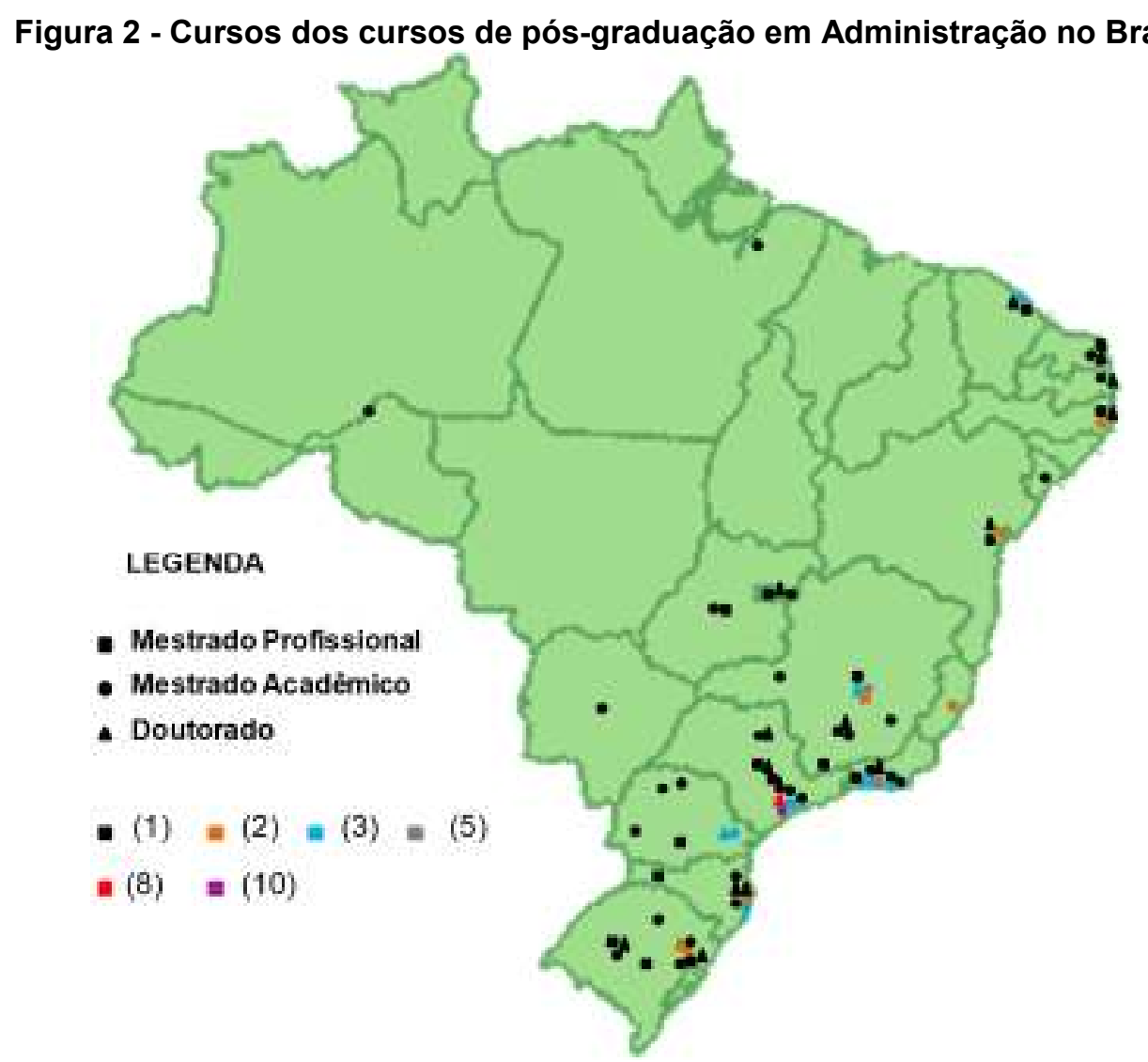

Fonte: Dados da pesquisa (2014).

É possível observar na Figura 2 que existe concentração de ofertas nas regiões Sudeste e Sul, com 41 e 22 programas, respectivamente. As outras regiões, como Norte e Centro-oeste, possuem pouca representatividade, no entanto, vale salientar que os programas recomendados e reconhecidos pela CAPES (2014) se encontram presentes em todas as regiões do país.

Nas regiões Norte, Nordeste e Centro-oeste, os programas são ofertados apenas nas capitais dos Estados, diferente do que ocorrem nas outras regiões, onde a distribuição é mais uniforme abrangendo localidades mais distantes das capitais, bem como regiões metropolitanas.

O Estado de São Paulo é o responsável por 17 programas, ou seja, 21,3\% das ofertas atuais, sendo o Estado que mais oferece pós-graduações na área atualmente. Além disso, concentra o mesmo número de programas das regiões Norte, Nordeste e Centro-oeste juntas, com 2, 4 e 11 cursos, respectivamente. 


\section{Mapeamento das linhas de pesquisa da pós-graduação em Administração no Brasil}

É importante destacar que, os programas de pós-graduação em Administração possuem 11 divisões acadêmicas estabelecidas pela ANPAD (2014), com seus respectivos temas de interesse em pesquisa conforme segue no Quadro 1.

\section{Quadro 1 - Linhas de pesquisas definidas pela ANPAD}

continua

\begin{tabular}{|c|c|}
\hline Linhas & Temas de interesse \\
\hline $\begin{array}{c}\text { Administração } \\
\text { da Informação } \\
\text { (ADI) }\end{array}$ & $\begin{array}{l}\text { 1- Aspectos Sociais, Culturais e Comportamentais dos Sistemas de Informação (SI) } \\
2 \text { - Desenvolvimento de Sistemas de Informação } \\
3 \text { - Gestão da Informação } \\
4 \text { - Gestão do Conhecimento (GC) } \\
5 \text { - Governança e Gestão de Tecnologia da Informação } \\
6 \text { - Processo Decisório e Sistemas de Apoio à Decisão (SAD) } \\
7 \text { - Metodologias, Métodos e Técnicas } \\
8 \text { - Sistemas de Informação Organizacionais e Interorganizacionais } \\
9 \text { - SI/TI em Organizaços Públicas e ONGs/Aspectos Socioambientais de SI/TI } \\
10 \text { - Sistemas de Informação e Gestão de Projetos }\end{array}$ \\
\hline $\begin{array}{l}\text { Administração } \\
\text { Pública (APB) }\end{array}$ & $\begin{array}{l}1 \text { - Estado, Sociedade, Governo e Administração Pública } \\
2 \text { - Relações entre Estado e Sociedade solidária. } \\
3 \text { - Federalismo, Relações Intergovernamentais e Descentralização } \\
4 \text { - Análise de Políticas Públicas } \\
5 \text { - Casos e Aplicações em Políticas Públicas } \\
6 \text { - Planejamento, Finanças e Controle no Setor Público } \\
7 \text { - Organização e Gestão de Serviços Públicos } \\
8 \text { - Gerenciamento de Organizações Públicas: Funções Gerenciais e Áreas Funcionais } \\
9 \text { - Gerenciamento de Organizações Públicas: Áreas Funcionais II e Abordagens Emergentes } \\
10 \text { - Teorias e Metodologias em Administração Pública as perspectivas metodológicas em } \\
\text { administração pública. } \\
11 \text { - História, Memória e Construção de Agendas de Pesquisa }\end{array}$ \\
\hline $\begin{array}{c}\text { Contabilidade } \\
\text { (CON) }\end{array}$ & $\begin{array}{l}1 \text { - Contabilidade e Governança Corporativa } \\
2 \text { - Contabilidade e Responsabilidade Socioambiental } \\
3 \text { - Contabilidade Financeira } \\
4 \text { - Contabilidade Governamental do Terceiro Setor } \\
5 \text { - Controladoria e Contabilidade Gerencial } \\
6 \text { - Auditoria e Perícia } \\
7 \text { - Contabilidade e Abordagens Comportamentais } \\
8 \text { - Contabilidade e Gestão Tributária }\end{array}$ \\
\hline $\begin{array}{l}\text { Estudos } \\
\text { Organizacionais } \\
\text { (EOR) }\end{array}$ & $\begin{array}{l}1 \text { - Abordagem Institucional nos Estudos Organizacionais } \\
2 \text { - Comportamento e Interações Sociais nas Organizações } \\
3 \text { - Trabalho, Organização e Sociedade } \\
4 \text { - Ontologia, Epistemologias, Teorias e Metodologias nos Estudos Organizacionais } \\
5 \text { - Estudos Críticos e Práticas Transformadoras em Organizações } \\
6 \text { - Gênero e Diversidade } \\
7 \text { - Redes e Relacionamentos Organizacionais } \\
8 \text { - Simbolismos, Culturas e Identidades em Organizações } \\
9 \text { - História, Memória, Processos Discursivos e Produção de Sentidos } \\
10 \text { - Prática de Gestão e Teorias de Administração em Estudos Organizacionais }\end{array}$ \\
\hline
\end{tabular}


Quadro 1 - Linhas de pesquisas definidas pela ANPAD

continua

\begin{tabular}{|c|c|}
\hline Linhas & Temas de interesse \\
\hline $\begin{array}{c}\text { Ensino e } \\
\text { Pesquisa em } \\
\text { Administração e } \\
\text { Contabilidade } \\
\text { (EPQ) }\end{array}$ & $\begin{array}{l}1 \text { - Epistemologia e Administração } \\
2 \text { - Estratégias e Métodos de Pesquisa Quantitativos e Qualitativos } \\
3 \text { - Conduta Ética e Responsável no Ensino e na Pesquisa } \\
4 \text { - Formação do Professor e do Pesquisador } \\
5 \text { - Aprendizagem e Formação Acadêmica } \\
6 \text { - Ação Docente e Ambiente de Aprendizagem } \\
7 \text { - Planejamento e Organização de Cursos e Programas } \\
8 \text { - O Contexto Institucional do Ensino e da Pesquisa } \\
9 \text { - Estudos Históricos, Reflexivos ou Críticos sobre as Áreas de Administração e Contabilidade } \\
10 \text { - Casos para Ensino em Administração e Contabilidade }\end{array}$ \\
\hline $\begin{array}{c}\text { Estratégia em } \\
\text { Organizações } \\
\text { (ESO) }\end{array}$ & $\begin{array}{l}1 \text { - Aspectos Teóricos e Metodológicos da Vantagem Competitiva } \\
2 \text { - Formulação, Implementação e Mudança das Estratégias } \\
3 \text { - Estratégia e Conhecimento } \\
4 \text { - Estratégias Empresariais e Corporativas } \\
5 \text { - Estratégia, Sustentabilidade Socioambiental e Ética Corporativa } \\
6 \text { - Estratégia e Empreendedorismo } \\
7 \text { - Estratégia e Cooperação } \\
8 \text { - Negócios Internacionais } \\
9 \text { - Modelagem e Mensuração do Desempenho } \\
10 \text { - Perspectivas Organizacionais e Sociológicas da Estratégia } \\
11 \text { - Estratégia, Governo e Desenvolvimento }\end{array}$ \\
\hline Finanças (FIN) & $\begin{array}{l}1 \text { - Estrutura de Capital, Dividendos e Capital de Giro } \\
2 \text { - Governança, Fusões e Aquisições e Estrutura de Propriedade } \\
3 \text { - Gestão de Riscos e Derivativos } \\
4 \text { - Investimento e Apreçamento de Ativos } \\
5 \text { - Mercados e Instituições Financeiras } \\
6 \text { - Finanças Comportamentais }\end{array}$ \\
\hline $\begin{array}{c}\text { Gestão de } \\
\text { Ciência, } \\
\text { Tecnologia e } \\
\text { Inovação (GCT) }\end{array}$ & $\begin{array}{l}1 \text { - Sistemas Nacionais, Regionais e Setoriais de Inovação } \\
2 \text { - Inovação e Empreendedorismo } \\
3 \text { - Inovação e Redes Organizacionais } \\
4 \text { - Inovação Organizacional e de Negócios } \\
5 \text { - Inovação e Cultura } \\
6 \text { - Inovação, Tecnologia e Competitividade } \\
7 \text { - Política e Gestão Estratégica de Ciência, Tecnologia e Inovação } \\
8 \text { - Inovação e Sustentabilidade }\end{array}$ \\
\hline $\begin{array}{c}\text { Gestão de } \\
\text { Operações e } \\
\text { Logística (GOL) }\end{array}$ & $\begin{array}{l}1 \text { - Gestão de Compras e Relacionamentos entre Compradores e Fornecedores } \\
2 \text { - Estratégia e Gestão de Operações Industriais } \\
3 \text { - Logística e Supply Chain Management } \\
4 \text { - Estratégia e Gestão de Operações de Serviços } \\
5 \text { - Operações Sustentáveis } \\
6 \text { - Redes de Operações e Clusters em Agronegócios, Indústrias e Serviços } \\
7 \text { - Modelagem Aplicada à Gestão de Operações } \\
8 \text { - Organizações da Área de Saúde: Administração das Operações e da Cadeia de Valor }\end{array}$ \\
\hline $\begin{array}{c}\text { Gestão de } \\
\text { Pessoas e } \\
\text { Relações de } \\
\text { Trabalho (GPR) }\end{array}$ & $\begin{array}{l}1 \text { - Trabalho e Diversidade } \\
2 \text { - Gestão de Carreiras } \\
3 \text { - Mudanças e Permanências nas Relações de Trabalho } \\
4 \text { - Liderança e Desenvolvimento Gerencial } \\
5 \text { - Prazer e Sofrimento no Trabalho } \\
6 \text { - Trabalho, Gestão e Subjetividade } \\
7 \text { - Políticas, Modelos e Práticas de/em Gestão de Pessoas } \\
8 \text { - Conhecimento e Aprendizagem } \\
9 \text { - Competências } \\
10 \text { - Gestão de Pessoas, Relações de Trabalho e Comportamento Organizacional }\end{array}$ \\
\hline
\end{tabular}


Quadro 1 - Linhas de pesquisas definidas pela ANPAD

continuação

\begin{tabular}{|c|l|}
\hline \multicolumn{1}{|c|}{ Linhas } & \multicolumn{1}{c|}{ Temas de interesse } \\
\hline & 1 - Comportamento do Consumidor I \\
& 2 - Comportamento do Consumidor II \\
3 - Cultura e Consumo & 4 - Métodos de Pesquisa e Teoria em Marketing \\
Marketing (MKT) & - Estratégias de Marketing e Marketing Internacional \\
& 6 - Marketing de Serviços e de Relacionamento \\
& 7 - Marketing e Sociedade \\
& 8 - Gestão do Varejo e da Distribuição \\
& - - Gestão do Composto de Marketing \\
& 10 - Inovação, Tecnologia e Interatividade \\
\hline
\end{tabular}

Fonte: ANPAD (2014).

Verifica-se no Quadro 1 que a ANPAD (2014) estabelece 11 grandes áreas de pesquisa composta por seus respectivos temas de interesse. O levantamento realizado através das páginas dos programas de cada IES demonstrou, em sua maioria, a adoção de áreas afins as estipuladas pela ANPAD o que necessitou de um enquadramento uma a uma a fim de identificar a área de concentração de cada programa.

Pela amplitude das linhas de pesquisa definidas pela ANPAD diversos programas de pós-graduação possuem mais de um foco de pesquisa, como pode ser observado através do Quadro 2 (APÊNDICE).

Salienta-se que a nomenclatura dos programas observadas no Quadro 2 foi baseada nas informações contidas no site da CAPES (2014). Deste modo, percebe-se que, dentre os 80 programas ofertados, 15 são mais específicos em sua denominação, como: (1) Administração de Empresas; (2) Administração de Micro e Pequenas Empresas; (3) Administração Pública e Governo; (4) Administração Pública; (5) Administração e Negócios; (6) Administração e Controladoria; (7) Administração e Desenvolvimento Rural; (8) Administração em Desenvolvimento Empresarial; (9) Administração Universitária; e (10) Administração de Organizações.

No Quadro 2 é possível observar também que poucas IES apresentam apenas 01 linha de pesquisa, sendo a maioria com conceitos baixos como 3 e 4 . Dos 14 programas que trabalham com apenas 01 linha, 08 são oferecidos na modalidade de Mestrado Profissional. Outro dado relevante é que os únicos programas melhores avaliados - com conceito 6 e 7 - estão localizados na região Sudeste.

\section{Distribuição geográfica por linha de pesquisa}

Atualmente, os 80 programas de Pós-graduação em Administração possuem 215 linhas distribuídas conforme as 11 áreas estabelecidas pela ANPAD (2014). Sendo assim, a partir do mapeamento realizado, a seguir, apresenta-se nas Figuras 3 a 8 a distribuição geográfica de cada linha de pesquisa.

Deste modo, no caso da linha ADI, representada pela Figura 3, nota-se que a mesma está presente em poucos programas, em sua maioria na região Sudeste. Já a linha APB encontra-se em 14 dos 80 programas, prevalecendo na região Sudeste $50 \%$ das linhas distribuídas pelo país. 


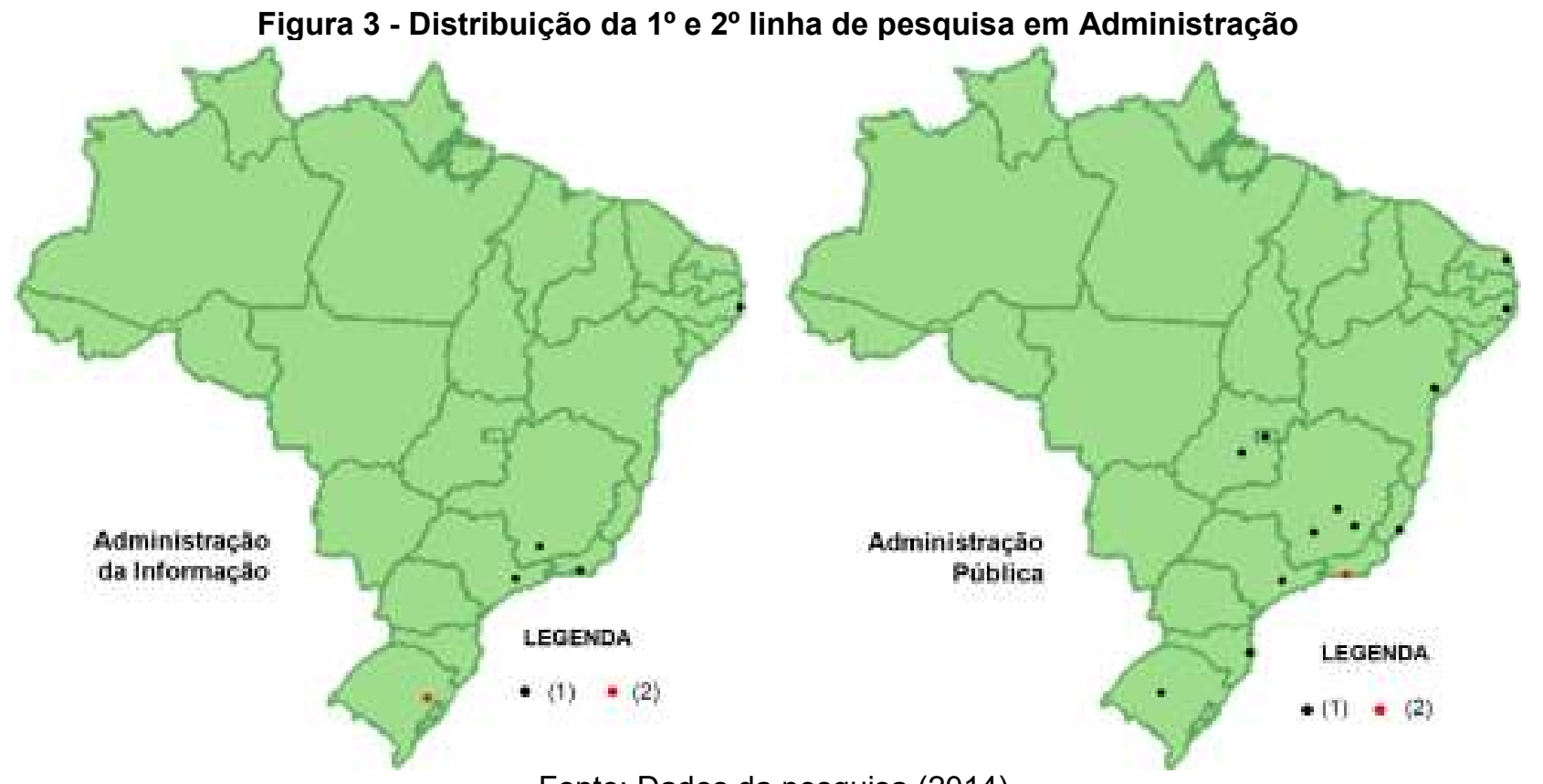

Fonte: Dados da pesquisa (2014).

Na Figura 4 tem-se a área de pesquisa CON, localizada em apenas dois Estados, Ceará e Minas Gerais. Ao lado, a linha EOR é a que mais está presente nos programas, atuando em todas as pósgraduações do Estado de Santa Catarina.

Figura 4 - Distribuição da $3^{\circ}$ e $4^{\circ}$ linha de pesquisa em Administração
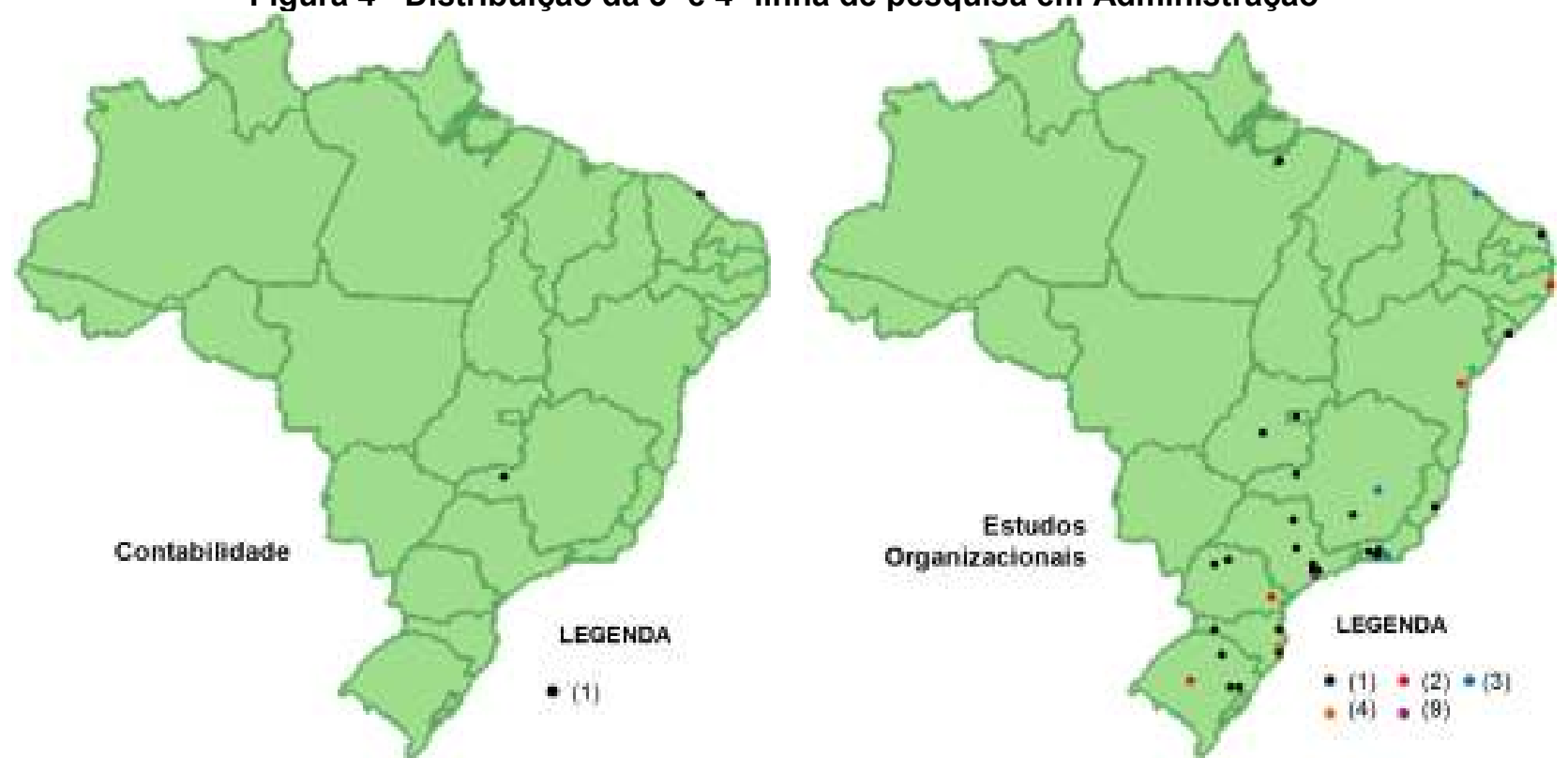

Fonte: Dados da pesquisa (2014). 
Na sequência, pode-se observar na Figura 5 que a área de pesquisa EPQ está localizada apenas na cidade de Salvador, na Bahia. Enquanto que a área ESO possui uma grande abrangência estando presente em todas as regiões do país conforme segue.

Figura 5 - Distribuição da $5^{\circ}$ e $6^{\circ}$ linha de pesquisa em Administração
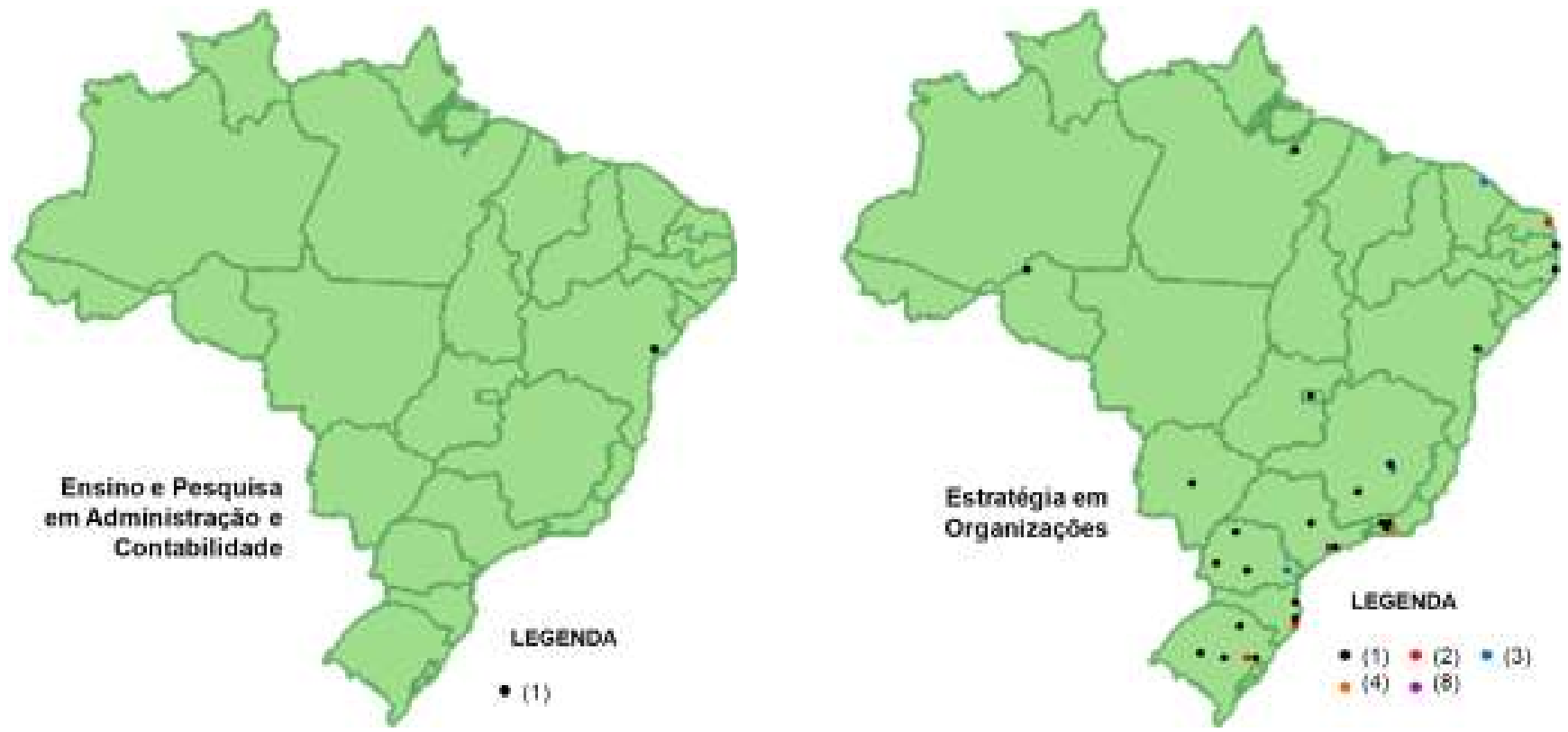

Fonte: Dados da pesquisa (2014).

Visualiza-se na Figura 6 que a área FIN tem seu foco de pesquisa nas IES do Sudeste, distribuída em todos os Estados da região. Já a $8^{\circ}$ linha é a GCT e, por sua vez, tem predominância nas regiões Sul e Sudeste.

Figura 6 - Distribuição da $7^{\circ}$ e $8^{\circ}$ linha de pesquisa em Administração
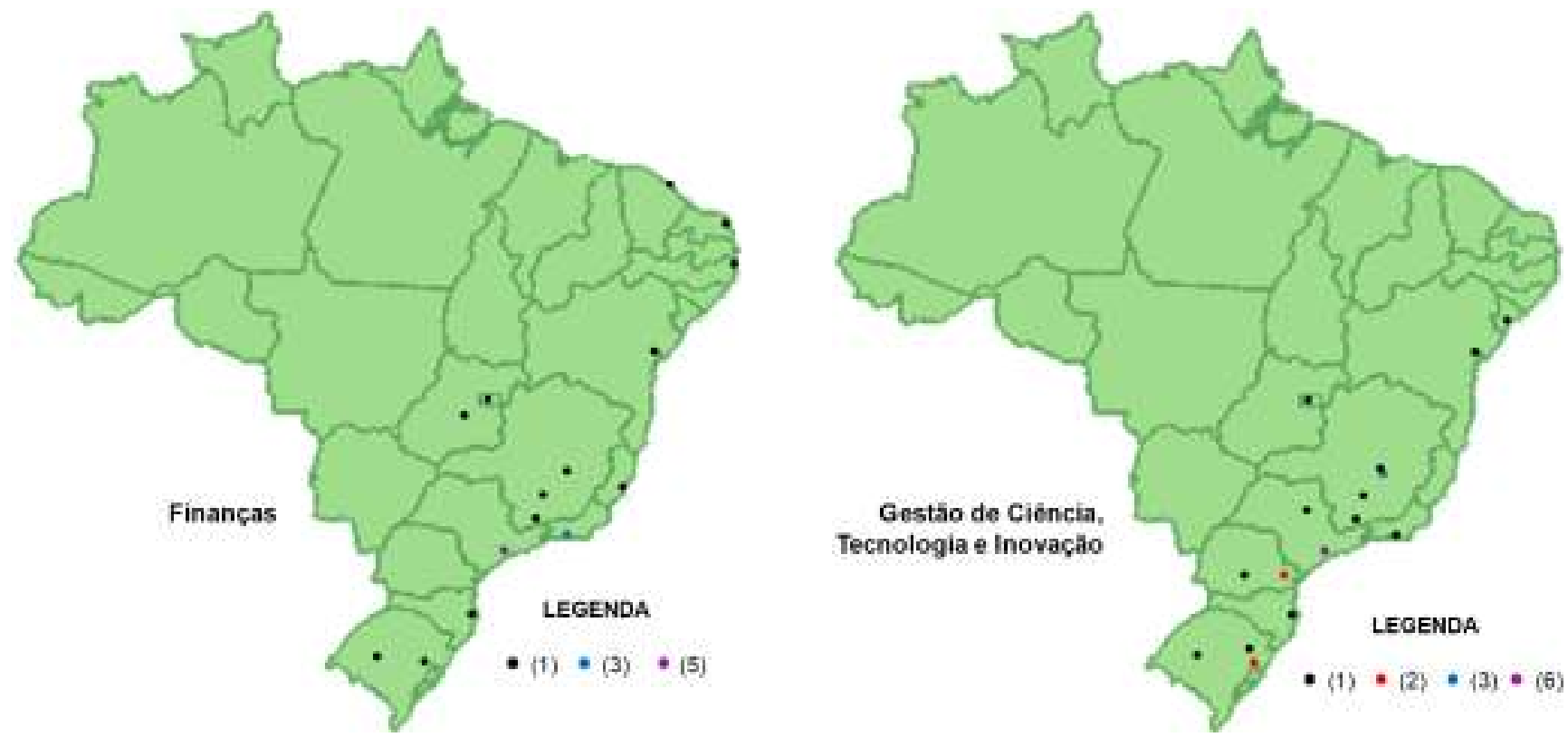

Fonte: Dados da pesquisa (2014). 
Constata-se, na Figura 7 que assim como a linha GCT que aparece apenas nas regiões Sul e Sudeste o mesmo ocorre com a linha GOL. Verifica-se, ao lado, a linha GPR com predominância nos Estados de São Paulo e Minas Gerais.

Figura 7: Distribuição da $9^{\circ}$ e $10^{\circ}$ linha de pesquisa em Administração
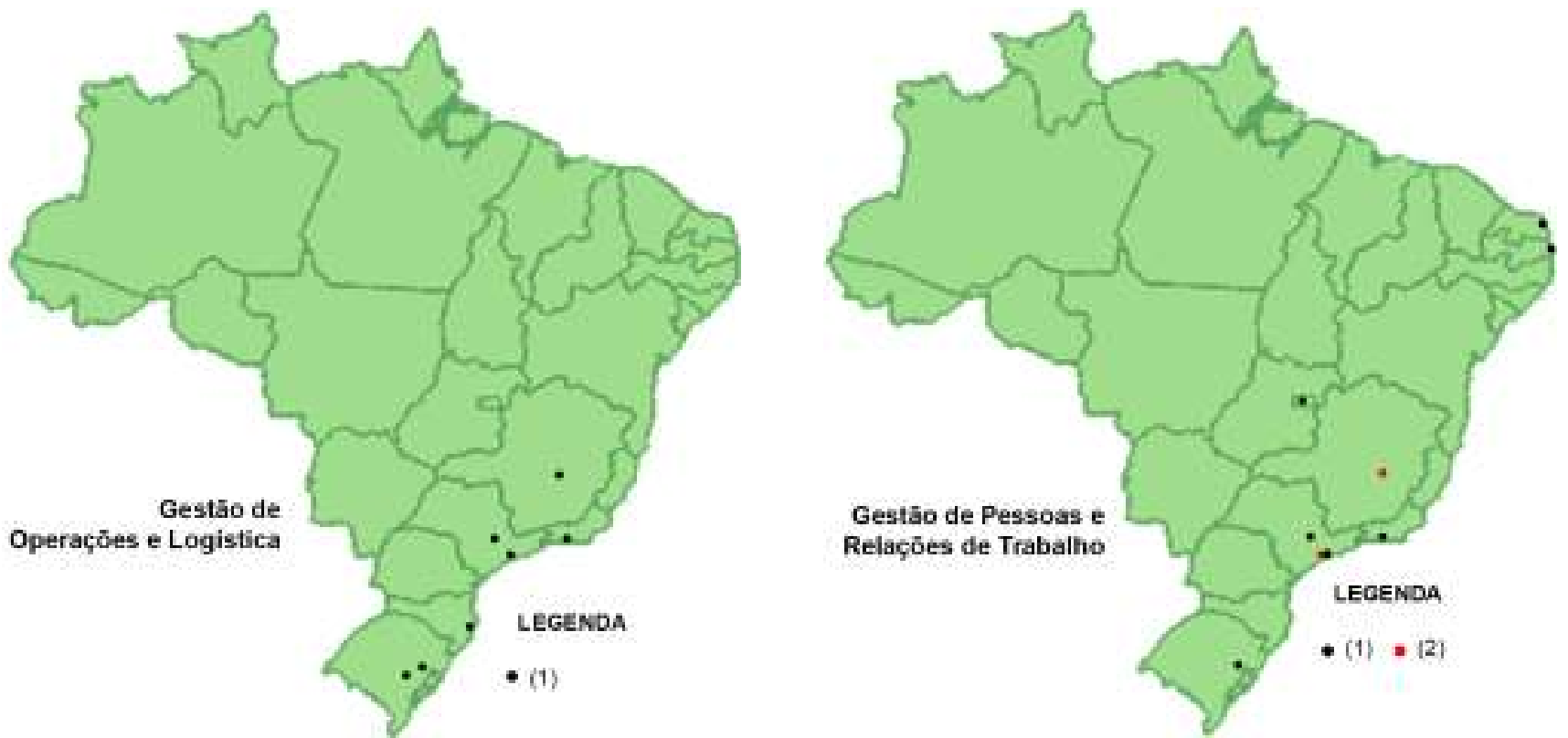

Fonte: Dados da pesquisa (2014).

A última linha de pesquisa apresentada é a de MKT, visualizada na Figura 8, concentrando seu foco de pesquisa nas regiões Sul e Sudeste, sendo este o responsável por reunir 59\% das linhas nessa área.

Figura 8 - Distribuição da $11^{\circ}$ linha de pesquisa em Administração

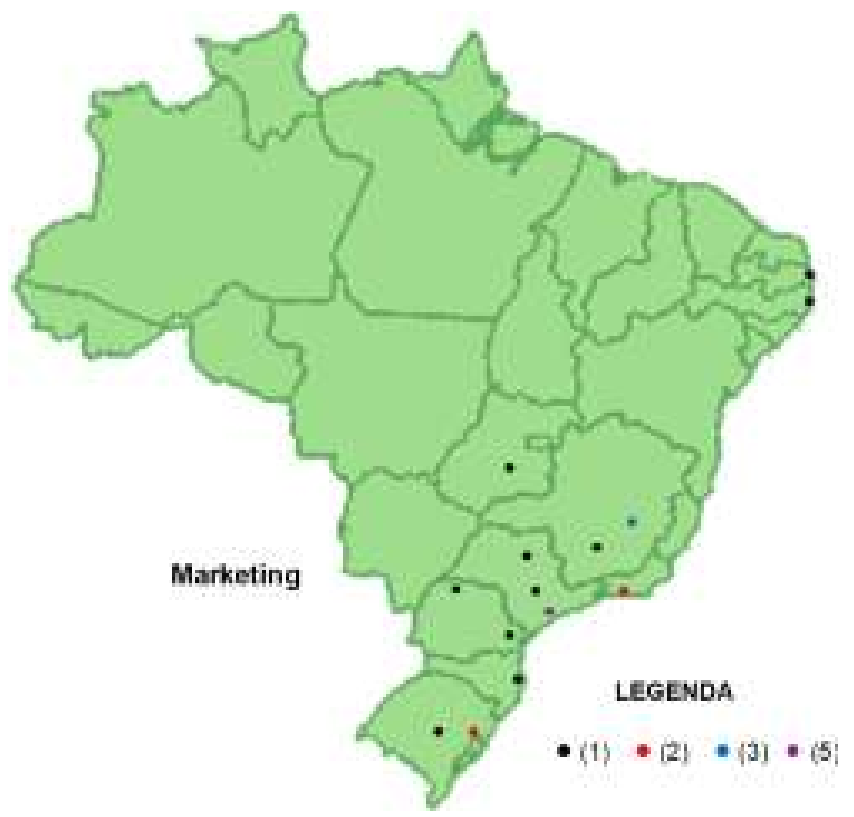

Fonte: Dados da pesquisa (2014). 
A partir do mapeamento realizado nota-se que, a distribuição das linhas de pesquisa ocorre de forma destoante, visto que a de Ensino e Pesquisa em Administração e Contabilidade aparece em apenas 01 programa. Enquanto que a linha Estudos Organizacionais consta em 54 programas, representando 67,5\%. Logo, é possível observar a diferença no foco dos programas de pós-graduação do país.

\section{Análise estatística dos dados}

Pela análise estatística dos dados verifica-se que, em relação às linhas de pesquisa, no Mestrado Acadêmico observa-se na Tabela 1 que Finanças e Administração da Informação alcançaram as maiores médias, 4,80 e 5,00, respectivamente. Já no Mestrado Profissional a maior média ficou com a linha de pesquisa Gestão de Pessoas e Relações de Trabalho $(3,80)$.

Enquanto que no Doutorado as linhas Administração Pública e Finanças tiveram as maiores médias, 5,25 e 5,27, respectivamente. Salienta-se que os conceitos atribuídos aos cursos de mestrado e Doutorado variam de 1 a 7.

Tabela 1 - Média e desvio padrão das linhas de pesquisa dos cursos de pós-graduação

\begin{tabular}{l|c|c|c|c|c|c}
\hline \multicolumn{1}{c}{ Linhas de pesquisa } & \multicolumn{3}{c}{ Média } & \multicolumn{3}{c}{ Desvio Padrão } \\
\cline { 2 - 7 } & \multicolumn{1}{c}{ MA } & \multicolumn{1}{c}{ MP } & \multicolumn{1}{c}{ MA } & \multicolumn{1}{c}{ MP } & \multicolumn{1}{c}{ D } \\
\hline ADI - Administração da Informação & 5,00 & 3,33 & 4,88 & 0,93 & 0,58 & 0,99 \\
APB - Administração Pública & 4,30 & 3,44 & 5,25 & 1,06 & 0,53 & 0,50 \\
CON - Contabilidade & 3,00 & - & - & - & - & - \\
EOR - Estudos Organizacionais & 4,32 & 3,45 & 4,88 & 1,07 & 0,51 & 0,90 \\
EPQ - Ensino e Pesquisa em Administração e Contabilidade & 3,00 & 3,00 & - & - & - & - \\
ESO - Estratégia em Organizações & 4,29 & 3,78 & 4,64 & 0,93 & 0,65 & 0,86 \\
FIN - Finanças & 4,80 & 3,64 & 5,27 & 1,21 & 0,63 & 1,01 \\
GCT - Gestão de Ciência, Tecnologia e Inovação & 4,38 & 3,53 & 4,88 & 1,02 & 0,64 & 0,96 \\
GOL - Gestão de Operações e Logística & 4,20 & 3,25 & 4,50 & 1,10 & 0,50 & 1,00 \\
GPR - Gestão de Pessoas e Relações de Trabalho & 4,46 & 3,80 & 4,90 & 1,20 & 0,79 & 0,99 \\
MKT - Marketing & 4,75 & 3,55 & 4,83 & 1,02 & 0,69 & 0,99 \\
\hline Total & $\mathbf{4 , 2 3}$ & $\mathbf{3 , 4 8}$ & $\mathbf{4 , 8 9}$ & $\mathbf{0 , 1 0}$ & $\mathbf{0 , 0 9}$ & $\mathbf{0 , 1 6}$ \\
\hline
\end{tabular}

Fonte: Dados da pesquisa (2014).

Sobre o desvio padrão, Lunet, Severo e Barros (2006) explicam que se trata de uma medida de dispersão que apresenta a variabilidade dos dados em relação à média. Assim sendo, nota-se que tanto no Mestrado Acadêmico como no Doutorado a linha de pesquisa em Finanças exibe a maior variabilidade com 1,21 e 1,01, respectivamente.

Enquanto que no Mestrado Profissional destaca-se a linha de Gestão de Pessoas e Relações de Trabalho com 0,79 de desvio padrão. Na Tabela 2 consta a matriz de correlação dos cursos com as linhas de pesquisa. 
Tabela 2 - Matriz de correlação dos cursos de pós-graduação e suas linhas de pesquisa

\begin{tabular}{l|r|r|r|r|r|r|r|r|r|r|r|r|r|r}
\hline & \multicolumn{1}{|c|}{ MA } & \multicolumn{1}{c|}{ MP } & \multicolumn{1}{c|}{ D } & ADI & APB & COM & EOR & EPQ & ESO & FIN & GCT & GOL & GPR & MKT \\
\hline MA & 1,00 & & & & & & & & & & & & & \\
MP & $-0,58$ & 1,00 & & & & & & & & & & & & \\
D & 0,72 & $-0,23$ & 1,00 & & & & & & & & & & & \\
ADI & 0,20 & 0,05 & 0,28 & 1,00 & & & & & & & & & & \\
APB & 0,03 & 0,07 & $-0,10$ & $-0,03$ & 1,00 & & & & & & & & & \\
COM & 0,02 & 0,06 & $-0,17$ & $-0,06$ & $-0,08$ & 1,00 & & & & & & & & \\
EOR & 0,32 & $-0,21$ & 0,33 & 0,02 & $-0,06$ & 0,11 & 1,00 & & & & & & & \\
EPQ & $-0,02$ & $-0,09$ & $-0,12$ & $-0,04$ & $-0,06$ & $-0,02$ & 0,08 & 1,00 & & & & & & \\
ESO & 0,19 & $-0,05$ & 0,28 & 0,25 & $-0,47$ & $-0,05$ & 0,01 & 0,09 & 1,00 & & & & & \\
FIN & 0,15 & 0,26 & 0,23 & 0,26 & 0,03 & 0,08 & 0,08 & $-0,07$ & 0,02 & 1,00 & & & & \\
GCT & 0,05 & 0,14 & 0,12 & 0,14 & 0,00 & $-0,11$ & 0,07 & $-0,08$ & 0,02 & 0,02 & 1,00 & & & \\
GOL & 0,00 & $-0,06$ & 0,13 & 0,05 & $-0,16$ & $-0,06$ & $-0,08$ & $-0,04$ & $-0,04$ & 0,11 & $-0,12$ & 1,00 & & \\
GPR & 0,07 & 0,22 & 0,24 & $-0,01$ & $-0,10$ & $-0,07$ & $-0,05$ & $-0,05$ & 0,08 & 0,34 & 0,05 & 0,25 & 1,00 & \\
MKT & 0,25 & 0,01 & 0,46 & 0,32 & $-0,30$ & $-0,11$ & $-0,04$ & $-0,07$ & 0,29 & 0,23 & 0,22 & 0,32 & 0,25 & 1,00 \\
\hline
\end{tabular}

Fonte: Dados da pesquisa (2014).

A correlação, por sua vez, mede o grau de relação entre duas variáveis, onde o sinal - positivo ou negativo - aponta a direção e o valor à intensidade da correlação existente entre essas variáveis (SAMPIERI; COLLADO; LUCIO, 2013).

Nesse sentido, Rumsey (2014) complementa que valores numéricos próximos a 1 ou -1 indica uma correlação forte; ao passo que próximos a 0 revela uma relação fraca ou inexistente; e por volta de 0,6 a 0,7 mostra uma correlação moderada.

Deste modo, conforme os valores visualizados na Tabela 2, percebe-se que apenas o Doutorado tem uma correlação moderada positiva com o Mestrado Acadêmico $(0,72)$, logo, pode-se dizer que um bom conceito em um dos cursos implica um bom conceito no outro, pois ambos se movem na mesma direção. Com relação às linhas de pesquisa nenhuma apresentou uma correlação forte, ou seja, todas tem uma relação fraca ou inexistente entre si. 


\section{CONSIDERAÇÕES FINAIS}

Entende-se que, na sociedade contemporânea, a interação entre as universidades e a sociedade requer políticas que favorecem a pesquisa acadêmica já que os benefícios do conhecimento gerado podem ajudar ambas as partes.

Assim, as universidades, juntamente com seus professores e alunos dos cursos de pós-graduação, podem se sentir desafiados a serem esses agentes integradores. Por um lado, a fim de fortalecer as pesquisas na área da Administração, tão carentes na produção científica no país, e por outro, usar esse conhecimento gerado em prol da sociedade.

Deste modo, contribuindo com pesquisa na área, a partir do levantamento realizado constatou-se a existência de 80 Programas de Pós-graduação em Administração no Brasil recomendados e reconhecidos pela CAPES (2014). Ao todo, identificou-se 127 opções entre Mestrado Acadêmico, Mestrado Profissional e Doutorado cuja maior concentração está nas regiões Sul e Sudeste devido o desenvolvimento econômico destas áreas.

Importante destacar que os programas melhores avaliados pela CAPES (conceito 6 e 7) encontramse todos na região Sudeste. Além disso, tornou-se evidente através da distribuição geográfica a escassez de cursos de pós-graduação na região Norte, havendo apenas 02 cursos de Mestrado Acadêmico, sendo 01 em Rondônia e outro no Pará, e nenhum curso de Mestrado Profissional ou Doutorado ofertado.

Diagnosticou-se também que existem 10 programas de pós-graduação já disponibilizados no site da CAPES, porém, encontram-se ainda em processo de homologação. Contudo, cabe destacar que durante a coleta de dados encontrou-se uma carência de informações apresentadas no site da CAPES e no site das IES responsáveis pelos programas como no caso da falta do endereço e link da instituição promotora do curso.

Em outros casos, o link existente da IES apresentado na página da CAPES direcionava para pósgraduações de outras áreas. Sendo assim, recomenda-se uma atualização mais frequente destas informações por parte das IES junto à base de dados da CAPES.

Ao findar esse estudo, acredita-se que novos possam ser realizados visando contribuir ainda mais ao tema incentivando novas pesquisas na área de pós-graduação tão carente no país. Por isso, sugere-se fazer um novo mapeamento, também por distribuição geográfica, todavia, agora considerando outros cursos de pós-graduação na área de Ciências Sociais Aplicadas no Brasil, e assim, fazer um levantamento de suas respectivas linhas de pesquisa e programas existentes. 


\section{REFERÊNCIAS}

ALMEIDA, M. H. T. A pós-graduação no Brasil: onde está e para onde poderia ir. Plano Nacional de Pós-Graduação PNPG 2011-2020. Documentos setoriais, v. II, Brasília: CAPES, 2010.

ANPAD - Associação Nacional dos Programas de Pós-Graduação em Administração. Divisões acadêmicas/comitês científicos/temas de interesse. 2014. Disponível em: <http://www.anpad.org.br/sobre_divisoes_academicas.php>. Acesso em: 10 mar. 2014.

CAPES - Coordenação de Aperfeiçoamento de Pessoal de Nível Superior. Plano nacional de pós-graduação (PNPG) 2011-2020. Brasília: CAPES, 2010.

Relação de cursos recomendados e reconhecidos. 2014. Disponível em:

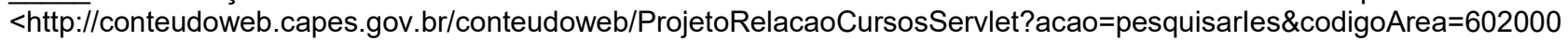
06\&descricaoArea\&descricaoAreaConhecimento=ADMINISTRA\%C7\%C3O\&descricaoAreaAvaliacao=ADMINISTRA \%C 7\%C3O\%2C+CI\%CANCIAS+CONT\%C1BEIS+E+TURISMO>. Acesso em: 10 mar. 2014.

CIRANI, C. B. S.; SILVA, H. H. M. da; CAMPANARIO, M. de A. A evolução do ensino da pós-graduação estrito senso em administração no Brasil. RAC, Rio de Janeiro, v. 16, n. 6, art. 1, p. 765-783, nov./dez. 2012.

FULGENCIO, P. C. Glossário vade mecum: administração pública, ciências contábeis, direito, economia, meio ambiente. Rio de Janeiro: Mauad X, 2007.

GAZZOLA, A. L. A.; FENALTI, R. A pós-graduação brasileira no horizonte de 2020. Plano Nacional de Pós-Graduação PNPG 2011-2020. Documentos setoriais, v. II, Brasília: CAPES, 2010.

GIL, A. C. Métodos e técnicas de pesquisa social. 6. ed. São Paulo: Atlas, 2012.

GONSALVES, E. P. Conversas sobre iniciação à pesquisa científica. 4. ed. Campinas: Alínea, 2012.

GRIFFIN, R. W. Introdução à administração. São Paulo: Ática, 2007.

GUIMARÃES, T. de A.; GOMES, A. de O.; ODELIUS, C. C.; ZANCAN, C.; CORRADI, A. A. A rede de programas de pósgraduação em administração no Brasil: análise de relações acadêmicas e atributos de programas. RAC, Curitiba, v. 13, n. 4, art. 3, p. 564-582, out./dez. 2009.

KWASNICKA, E. L. Introdução à administração. 6. ed. São Paulo: Atlas, 2007.

LUNET, N.; SEVERO, M.; BARROS, H. Desvio padrão ou erro padrão. Arquivos de Medicina, v. 20, n. 1/2, p. 55-59, 2006.

MACCARI, E. A.; COIMBRA, F. C.; RODRIGUES, L. C.; ALMEIDA, M. I. R. de. Aplicação do modelo de planejamento estratégico em um programa de pós-graduação stricto sensu em administração. Revista de Ciências da Administração, Florianópolis, v. 8, n. 16, jul./dez. 2006.

MACEDO, D. L. de; RODRIGUES, L. C.; SILVEIRA, A. Sistema de inteligência acadêmica na gestão de pós-graduação stricto sensu em administração. Revista de Ciências da Administração, Florianópolis, v. 13, n. 31, p. 136-160, set./dez. 2011.

MEC - Ministério da Educação. Pós-graduação stricto sensu: mestrado e doutorado. 2014. Disponível em: <http://mecsrv125.mec.gov.br/index.php?option=com_content\&view=article\&id=385\&ltemid=316>. Acesso em: 22 dez. 2014.

MELLO, C. M.; CRUBELLATE, J. M.; ROSSONI, L Dinâmica de relacionamento e prováveis respostas estratégicas de programas brasileiros de pós-graduação em administração à avaliação da capes: proposições institucionais a partir da análise de redes de co-autorias. RAC, Curitiba, v. 14, n. 3, art. 3, p. 434-457, maio/jun. 2010.

MORAES, M. H. M. de; GIROLDO, D. Distribuição geográfica da pós-graduação: estudo de indicadores. In. SEMINÁRIO DE PESQUISA EM EDUCAÇÃO DA REGIÃO SUL, 9., Caxias do Sul, 2012. Anais... Caxias do Sul: ANPED SUL, 2012.

NEUENFELDT, M. C.; ISAIA, S. M. A. Pós-graduação e a pós-graduação em educação no Brasil: um breve histórico. Revista de Educação PUC-Campinas, Campinas, n. 24, p. 85-95, jun. 2008.

OLIVEIRA, E. L.; SIQUEIRA, H. V. Avançar na pós-graduação e formar recursos humanos para o desenvolvimento do país. Plano Nacional de Pós-Graduação - PNPG 2011-2020. Documentos setoriais, v. II, Brasília: CAPES, 2010.

PAIVA, A. M. de. Rumos e perspectivas do egresso do programa de pós-graduação stricto sensu em educação PUCCampinas - (1993-2004). 154 f. 2006. Dissertação (Mestrado em Educação) - Programa de Pós-graduação em Educação - Pontifícia Universidade Católica de Campinas, Campinas, 2006.

REZENDE, S. M. Momentos da ciência e tecnologia no Brasil: uma caminhada de 40 anos pela C\&T. Rio de Janeiro: Vieira e Lent, 2010.

RUMSEY, D. Estatística II para leigos. Rio de Janeiro: Alta Books, 2014.

SAMPIERI, R. H.; COLLADO, C. F.; LUCIO, M. del P. B. Metodologia de pesquisa. 5. ed. São Paulo: McGrawGrill, 2013. 
SANTOS, A. L. F. dos; AZEVEDO, J. M. L. de. A pós-graduação no Brasil, a pesquisa em educação e os estudos sobre a política educacional: os contornos da constituição de um campo acadêmico. Revista Brasileira de Educação, Rio de Janeiro, v. 14, n. 42, p. 534-605, set./dez. 2009.

SANTOS, C. M. dos. Tradições e contradições da pós-graduação no Brasil. Educação \& Sociedade, Campinas, v. 24 , n. 83, p. 627-641, ago. 2003.

SANTOS, V. G. V. A administração científica e sua colaboração para as organizações do século XXI. Revista Eletrônica FACE, Espírito Santo, p. 1-13, 2014.

SCHWARTZMAN, S. Nota sobre a transição necessária da pós-graduação brasileira. Plano Nacional de Pós-Graduação - PNPG 2011-2020. Documentos setoriais, v. II, Brasília: CAPES, 2010.

SEVERINO, A. J. Metodologia do trabalho científico. 23. ed. São Paulo: Cortez, 2007.

SILVA JÚNIOR, J. dos R.; FERREIRA, L. R.; KATO, F. B. G. Trabalho do professor pesquisador diante da expansão da pós-graduação no Brasil pós-LDB. Revista Brasileira de Educação, Rio de Janeiro, v. 18, n. 53, p. 435-456, abr./jun. 2013.

SILVA, M. O. da S. e; CARVALHO, D. B. B. de. A pós-graduação e a produção de conhecimento no Serviço Social brasileiro. Revista Brasileira de Pós-Graduação, Brasília, v. 4, n. 8, p. 192-216, dez. 2007.

SOUZA, S. A.; REINERT, J. N. Participação discente nas publicações da pós-graduação: Um estudo comparativo entre programas públicos e provados de administração. Revista Avaliação, Campinas, v. 17, n. 2, p. 481-502, jul. 2012.

TAUCHEN, G; CORREA, N. V.; BORGES, D. S.; NEVES, C. F. P. Avaliação das estratégias da gestão da pós-graduação a partir do Programa de Excelência Acadêmica (PROEX). In: COLOQUIO DE GESTIÓN UNIVERSITARIA EN AMÉRICAS, 13., Buenos Aires, 2013. Anais... Buenos Aires, 2013.

VERGARA, S. C. Projetos e relatórios de pesquisa em administração. 15. ed. São Paulo: Atlas, 2014

\section{APÊNDICE}

Quadro 2 - Programas de Pós-graduação em Administração no Brasil

\begin{tabular}{|c|c|c|c|c|c|c|c|}
\hline \multirow{2}{*}{\multicolumn{2}{|c|}{ IES }} & \multirow{2}{*}{ Programa } & \multirow{2}{*}{ Área de Concentração } & \multirow{2}{*}{ UF } & \multicolumn{3}{|c|}{ CONCEITO } \\
\hline & & & & & $\mathbf{M}$ & D & $\mathbf{P}$ \\
\hline 1 & ALFA & Administração & $\begin{array}{l}\text { - Finanças } \\
\text { - Marketing }\end{array}$ & GO & - & - & 3 \\
\hline 2 & ESPM & Administração & $\begin{array}{l}\text { - Estratégia em Organizações } \\
\text { - Marketing }\end{array}$ & SP & 4 & 4 & - \\
\hline 3 & FACCAMP & $\begin{array}{l}\text { Administração das Micros e } \\
\text { Pequenas Empresas }\end{array}$ & - Estudos Organizacionais & SP & - & - & 4 \\
\hline 4 & FECAP & Administração & - Finanças & SP & - & - & 3 \\
\hline 5 & FEI & Administração & $\begin{array}{l}\text { - Estudos Organizacionais } \\
\text { - Estratégia em Organizações } \\
\text { - Gestão de Ciência, Tecnologia e } \\
\text { Inovação }\end{array}$ & SP & 4 & 4 & - \\
\hline 6 & FGV - RJ & Administração & $\begin{array}{l}\text { - Administração Pública } \\
\text { - Estudos Organizacionais }\end{array}$ & RJ & 6 & 6 & - \\
\hline 7 & FGV - RJ & Administração & - Administração Pública & $\mathrm{RJ}$ & - & - & 4 \\
\hline 8 & FGV - RJ & Administração & $\begin{array}{l}\text { - Estratégia em Organizações } \\
\text { - Finanças } \\
\text { - Gestão de Pessoas e Relações de } \\
\text { Trabalho }\end{array}$ & RJ & - & - & 5 \\
\hline 9 & $\begin{array}{l}\text { FGV - São } \\
\text { Paulo }\end{array}$ & Administração de Empresas & $\begin{array}{l}\text { - Administração da Informação } \\
\text { - Estudos Organizacionais } \\
\text { - Estratégia em Organizações } \\
\text { - Gestão de Ciência, Tecnologia e } \\
\text { Inovação } \\
\text { - Marketing } \\
\text { - Finanças }\end{array}$ & SP & 7 & 7 & 4 \\
\hline 10 & $\begin{array}{l}\text { FGV - São } \\
\text { Paulo }\end{array}$ & $\begin{array}{l}\text { Administração Pública e } \\
\text { Governo }\end{array}$ & $\begin{array}{l}\text { - Administração Pública } \\
\text { - Estudos Organizacionais }\end{array}$ & SP & 5 & 5 & - \\
\hline 11 & FJP & Administração Pública & - Administração Pública & MG & 5 & - & - \\
\hline 12 & FMU & Administração & $\begin{array}{l}\text { - Estudos Organizacionais } \\
\text { - Gestão de Ciência, Tecnologia e } \\
\text { Inovação } \\
\text { - Marketing }\end{array}$ & SP & $3^{*}$ & - & - \\
\hline
\end{tabular}




\begin{tabular}{|c|c|c|c|c|c|c|c|}
\hline 13 & $\mathrm{FNH}$ & Administração & $\begin{array}{l}\text { - Estratégia em Organizações } \\
\text { - Gestão de Ciência, Tecnologia e } \\
\text { Inovação }\end{array}$ & MG & 3 & - & - \\
\hline 14 & FPL & Administração & $\begin{array}{l}\text { - Estratégia em Organizações } \\
\text { - Gestão de Ciência, Tecnologia e } \\
\text { Inovação }\end{array}$ & MG & - & - & 3 \\
\hline 15 & FUCAPE & Administração de Empresas & $\begin{array}{l}\text { - Administração Pública } \\
\text { - Finanças }\end{array}$ & ES & 4 & - & - \\
\hline 16 & FUMEC & Administração & $\begin{array}{l}\text { - Estratégia em Organizações } \\
\text { - Marketing } \\
\text { - Estudos Organizacionais }\end{array}$ & MG & 4 & 4 & - \\
\hline 17 & FURB & Administração & $\begin{array}{l}\text { - Estudos Organizacionais } \\
\text { - Estratégia em Organizações }\end{array}$ & SC & 4 & - & - \\
\hline 18 & IBMEC & Administração & $\begin{array}{l}\text { - Estratégia em Organizações } \\
\text { - Finanças }\end{array}$ & RJ & - & - & 4 \\
\hline 19 & IMED & Administração & $\begin{array}{l}\text { - Estudos Organizacionais } \\
\text { - Estratégia em Organizações }\end{array}$ & RS & $3^{*}$ & - & - \\
\hline 20 & INSPER & Administração & - Estratégia em Organizações & SP & - & - & 4 \\
\hline & PUC & Administração & $\begin{array}{l}\text { - Estratégia em Organizações } \\
\text { - Gestão de Ciência, Tecnologia e } \\
\text { Inovação } \\
\text { - Gestão de Pessoas e Relações de } \\
\text { Trabalho } \\
\text { - Marketing }\end{array}$ & MG & 4 & 4 & 5 \\
\hline 22 & PUC & Administração & $\begin{array}{l}\text { - Administração da Informação } \\
\text { - Estratégia em Organizações } \\
\text { - Estudos Organizacionais }\end{array}$ & PR & 5 & 5 & - \\
\hline 23 & PUC & Administração de Empresas & $\begin{array}{l}\text { - Estudos Organizacionais } \\
\text { - Estratégia em Organizações } \\
\text { - Marketing } \\
\text { - Finanças }\end{array}$ & RJ & 5 & 5 & 4 \\
\hline 24 & PUC & Administração e Negócios & $\begin{array}{l}\text { - Administração da Informação } \\
\text { - Estratégia em Organizações } \\
\text { - Marketing } \\
\text { - Gestão de Ciência, Tecnologia e } \\
\text { Inovação }\end{array}$ & RS & 5 & 4 & - \\
\hline 25 & PUC & Administração & $\begin{array}{l}\text { - Estratégia em Organizações } \\
\text { - Gestão de Ciência, Tecnologia e } \\
\text { Inovação } \\
\text { - Estudos Organizacionais }\end{array}$ & SP & 4 & 4 & - \\
\hline 26 & UCS & Administração & $\begin{array}{l}\text { - Gestão de Ciência, Tecnologia e } \\
\text { Inovação } \\
\text { - Gestão de Operações e Logística }\end{array}$ & RS & 4 & - & - \\
\hline 27 & UDESC & Administração & $\begin{array}{l}\text { - Administração Pública } \\
\text { - Estudos Organizacionais } \\
\text { - Gestão de Ciência, Tecnologia e } \\
\text { Inovação }\end{array}$ & SC & 3 & - & 4 \\
\hline 28 & UECE & Administração & $\begin{array}{l}\text { - Estudos Organizacionais } \\
\text { - Estratégia em Organizações }\end{array}$ & CE & 4 & - & - \\
\hline 29 & UEL & Administração & - Estudos Organizacionais & $\mathrm{PR}$ & 3 & - & - \\
\hline 30 & UEM & Administração & $\begin{array}{l}\text { - Estudos Organizacionais } \\
\text { - Marketing } \\
\text { - Estratégia em Organizações }\end{array}$ & PR & 4 & $4^{*}$ & - \\
\hline 31 & UFBA & Administração & $\begin{array}{l}\text { - Administração Pública } \\
\text { - Estudos Organizacionais } \\
\text { - Gestão de Ciência, Tecnologia e } \\
\text { Inovação } \\
\text { - Finanças }\end{array}$ & BA & 5 & 5 & 4 \\
\hline 32 & UFC & Administração e Controladoria & $\begin{array}{l}\text { - Estudos Organizacionais } \\
\text { - Estratégia em Organizações } \\
\text { - Finanças } \\
\text { - Contabilidade }\end{array}$ & $\mathrm{CE}$ & 4 & - & 4 \\
\hline 33 & UFES & Administração & - Estudos Organizacionais & ES & 4 & $4^{*}$ & - \\
\hline 34 & UFF & Administração & $\begin{array}{l}\text { - Estudos Organizacionais } \\
\text { - Estratégia em Organizações }\end{array}$ & RJ & 3 & - & 3 \\
\hline 35 & UFG & Administração & - Administração Pública & GO & $3^{*}$ & - & - \\
\hline
\end{tabular}




\begin{tabular}{|c|c|c|c|c|c|c|c|}
\hline & & & - Estudos Organizacionais & & & & \\
\hline & UFLA & Administração & $\begin{array}{l}\text { - Gestão de Ciência, Tecnologia e } \\
\text { Inovação } \\
\text { - Marketing } \\
\text { - Estratégia em Organizações } \\
\text { - Estudos Organizacionais } \\
\text { - Finanças }\end{array}$ & MG & 5 & 5 & - \\
\hline 37 & UFLA & Administração Pública & - Administração Pública & MG & - & - & 3 \\
\hline & UFMG & Administração & $\begin{array}{l}\text { - Estudos Organizacionais } \\
\text { - Finanças } \\
\text { - Gestão de Operações e Logística } \\
\text { - Gestão de Pessoas e Relações de } \\
\text { Trabalho } \\
\text { - Marketing }\end{array}$ & MG & 6 & 6 & - \\
\hline & UFMS & Administração & - Estratégia em Organizações & MS & 4 & - & - \\
\hline & UFPB & Administração & $\begin{array}{l}\text { - Gestão de Pessoas e Relações de } \\
\text { Trabalho } \\
\text { - Estratégia em Organizações } \\
\text { - Marketing }\end{array}$ & PB & 5 & 5 & - \\
\hline 41 & UFPE & Administração & $\begin{array}{l}\text { - Administração da Informação } \\
\text { - Estratégia em Organizações } \\
\text { - Estudos Organizacionais } \\
\text { - Finanças } \\
\text { - Marketing }\end{array}$ & PE & 4 & 4 & 3 \\
\hline 42 & UFPR & Administração & $\begin{array}{l}\text { - Gestão de Ciência, Tecnologia e } \\
\text { Inovação } \\
\text { - Marketing } \\
\text { - Estratégia em Organizações }\end{array}$ & PR & 4 & 4 & - \\
\hline 43 & UFRGS & Administração & $\begin{array}{l}\text { - Administração da Informação } \\
\text { - Estratégia em Organizações } \\
\text { - Estudos Organizacionais } \\
\text { - Finanças } \\
\text { - Gestão de Ciência, Tecnologia e } \\
\text { Inovação } \\
\text { - Marketing } \\
\text { - Gestão de Pessoas e Relações de } \\
\text { Trabalho }\end{array}$ & RS & 5 & 5 & 3 \\
\hline 44 & UFRJ & Administração & $\begin{array}{l}\text { - Estratégia em Organizações } \\
\text { - Gestão de Operações e Logística } \\
\text { - Marketing } \\
\text { - Administração da Informação }\end{array}$ & RJ & 4 & 4 & - \\
\hline 45 & UFRN & Administração & $\begin{array}{l}\text { - Administração da Informação } \\
\text { - Administração Pública } \\
\text { - Estratégia em Organizações } \\
\text { - Estudos Organizacionais } \\
\text { - Finanças }\end{array}$ & RN & 5 & 5 & - \\
\hline 46 & UFRPE & $\begin{array}{l}\text { Administração e } \\
\text { Desenvolvimento Rural }\end{array}$ & $\begin{array}{l}\text { - Administração Pública } \\
\text { - Estudos Organizacionais }\end{array}$ & $\mathrm{PE}$ & 3 & - & - \\
\hline 47 & UFRRJ & Administração & $\begin{array}{l}\text { - Estudos Organizacionais } \\
\text { - Estratégia em Organizações }\end{array}$ & RJ & $3^{*}$ & - & - \\
\hline 48 & UFSC & Administração & $\begin{array}{l}\text { - Estudos Organizacionais } \\
\text { - Finanças } \\
\text { - Gestão de Operações e Logística } \\
\text { - Marketing } \\
\text { - Estratégia em Organizações }\end{array}$ & SC & 4 & 4 & - \\
\hline 49 & UFSC & Administração Universitária & - Estudos Organizacionais & $\mathrm{SC}$ & - & - & 3 \\
\hline 50 & UFSE & Administração & $\begin{array}{l}\text { - Estudos Organizacionais } \\
\text { - Gestão de Ciência, Tecnologia e } \\
\text { Inovação }\end{array}$ & SE & 3 & - & - \\
\hline 51 & UFSM & Administração & $\begin{array}{l}\text { - Estratégia em Organizações } \\
\text { - Estudos Organizacionais } \\
\text { - Finanças }\end{array}$ & RS & 4 & 4 & - \\
\hline 52 & UFSM & Administração & $\begin{array}{l}\text { - Administração Pública } \\
\text { - Estudos Organizacionais } \\
\text { - Gestão de Ciência, Tecnologia e } \\
\text { Inovação }\end{array}$ & RS & - & - & 3 \\
\hline
\end{tabular}




\begin{tabular}{|c|c|c|c|c|c|c|c|}
\hline 53 & UFU & Administração & $\begin{array}{l}\text { - Contabilidade } \\
\text { - Estudos Organizacionais }\end{array}$ & MG & 3 & - & - \\
\hline 54 & UFV & Administração & - Administração Pública & MG & 4 & - & - \\
\hline 55 & UMESP & Administração & $\begin{array}{l}\text { - Estudos Organizacionais } \\
\text { - Finanças } \\
\text { - Gestão de Pessoas e Relações de } \\
\text { Trabalho }\end{array}$ & SP & 3 & - & - \\
\hline 56 & UNA & Administração & $\begin{array}{l}\text { - Estudos Organizacionais } \\
\text { - Gestão de Ciência, Tecnologia e } \\
\text { Inovação }\end{array}$ & MG & - & - & 3 \\
\hline 57 & UNAMA & Administração & $\begin{array}{l}\text { - Estudos Organizacionais } \\
\text { - Estratégia em Organizações }\end{array}$ & PA & 4 & $4^{*}$ & - \\
\hline 58 & UNB & Administração & $\begin{array}{l}\text { - Administração Pública } \\
\text { - Estudos Organizacionais } \\
\text { - Estratégia em Organizações } \\
\text { - Finanças } \\
\text { - Gestão de Ciência, Tecnologia e } \\
\text { Inovação } \\
\text { - Gestão de Pessoas e Relações de } \\
\text { Trabalho }\end{array}$ & DF & 5 & 5 & 4 \\
\hline 59 & UNESA & $\begin{array}{l}\text { Administração e } \\
\text { Desenvolvimento Empresarial }\end{array}$ & $\begin{array}{l}\text { - Estudos Organizacionais } \\
\text { - Gestão de Ciência, Tecnologia e } \\
\text { Inovação }\end{array}$ & RJ & - & - & 4 \\
\hline 60 & UNICENTRO & Administração & $\begin{array}{l}\text { - Estratégia em Organizações } \\
\text { - Gestão de Ciência, Tecnologia e } \\
\text { Inovação }\end{array}$ & PR & - & - & $3^{*}$ \\
\hline 61 & UNIFACS & Administração & $\begin{array}{l}\text { - Ensino e Pesquisa em Administração } \\
\text { e Contabilidade } \\
\text { - Estudos Organizacionais } \\
\text { - Estratégia em Organizações }\end{array}$ & $\mathrm{BA}$ & 3 & - & - \\
\hline 62 & UNIFEI & Administração & $\begin{array}{l}\text { - Gestão de Ciência, Tecnologia e } \\
\text { Inovação } \\
\text { - Finanças } \\
\text { - Administração da Informação }\end{array}$ & MG & - & - & $3^{*}$ \\
\hline 63 & UNIFOR & Administração de Empresas & $\begin{array}{l}\text { - Estudos Organizacionais } \\
\text { - Estratégia em Organizações }\end{array}$ & CE & 4 & 4 & - \\
\hline 64 & UNIGRANRIO & Administração & $\begin{array}{l}\text { - Estudos Organizacionais } \\
\text { - Estratégia em Organizações }\end{array}$ & RJ & 4 & 4 & - \\
\hline 65 & UNIMEP & Administração & $\begin{array}{l}\text { - Estudos Organizacionais } \\
\text { - Estratégia em Organizações } \\
\text { - Gestão de Pessoas e Relações de } \\
\text { Trabalho } \\
\text { - Gestão de Operações e Logística } \\
\text { - Marketing }\end{array}$ & $\mathrm{SP}$ & - & 4 & 4 \\
\hline 66 & UNINOVE & Administração & $\begin{array}{l}\text { - Estudos Organizacionais } \\
\text { - Estratégia em Organizações } \\
\text { - Marketing } \\
\text { - Gestão de Ciência, Tecnologia e } \\
\text { Inovação }\end{array}$ & SP & 5 & 5 & - \\
\hline 67 & UNIOESTE & Administração & - Estratégia em Organizações & PR & - & - & $3^{*}$ \\
\hline 68 & UNIP & Administração & $\begin{array}{l}\text { - Estudos Organizacionais } \\
\text { - Estratégia em Organizações }\end{array}$ & $\mathrm{SP}$ & 3 & - & - \\
\hline 69 & UNIR & Administração & - Estratégia em Organizações & $\mathrm{RO}$ & 4 & - & - \\
\hline 70 & UNISC & Administração & $\begin{array}{l}\text { - Estratégia em Organizações - Gestão } \\
\text { de Operações e Logística } \\
\text { - Marketing }\end{array}$ & RS & - & - & 3 \\
\hline 71 & UNISINOS & Administração & $\begin{array}{l}\text { - Estudos Organizacionais } \\
\text { - Estratégia em Organizações }\end{array}$ & RS & 5 & 5 & - \\
\hline 72 & UNISUL & Administração & $\begin{array}{l}\text { - Estudos Organizacionais } \\
\text { - Estratégia em Organizações }\end{array}$ & SC & 3 & - & - \\
\hline 73 & UNIVALI & Administração & $\begin{array}{l}\text { - Estudos Organizacionais } \\
\text { - Estratégia em Organizações }\end{array}$ & $\mathrm{SC}$ & 5 & 5 & - \\
\hline 74 & UNOESC & Administração & - Estudos Organizacionais & SC & - & - & 3 \\
\hline 75 & UNP & Administração & $\begin{array}{l}\text { - Gestão de Pessoas e Relações de } \\
\text { Trabalho } \\
\text { - Estratégia em Organizações }\end{array}$ & $\mathrm{RN}$ & - & - & 4 \\
\hline
\end{tabular}




\begin{tabular}{|c|c|c|c|c|c|c|c|}
\hline & UP & Administração & $\begin{array}{l}\text { - Estudos Organizacionais } \\
\text { - Estratégia em Organizações } \\
\text { - Gestão de Ciência, Tecnologia e } \\
\text { Inovação }\end{array}$ & PR & 4 & 4 & \\
\hline 77 & UPM & Administração de Empresas & $\begin{array}{l}\text { - Estudos Organizacionais } \\
\text { - Gestão de Pessoas e Relações de } \\
\text { Trabalho } \\
\text { - Finanças } \\
\text { - Gestão de Operações e Logística }\end{array}$ & SP & 5 & 5 & \\
\hline 78 & USCS & Administração & $\begin{array}{l}\text { - Estudos Organizacionais } \\
\text { - Estratégia em Organizações }\end{array}$ & $S P$ & 5 & 5 & - \\
\hline 79 & USP - FEA & Administração & $\begin{array}{l}\text { - Estudos Organizacionais } \\
\text { - Estratégia em Organizações } \\
\text { - Finanças } \\
\text { - Gestão de Ciência, Tecnologia e } \\
\text { Inovação } \\
\text { - Gestão de Pessoas e Relações de } \\
\text { Trabalho } \\
\text { - Marketing }\end{array}$ & SP & 7 & 7 & \\
\hline 80 & USP - FEARP & $\begin{array}{l}\text { Administração de } \\
\text { Organizações }\end{array}$ & $\begin{array}{l}\text { - Gestão de Ciência, Tecnologia e } \\
\text { Inovação } \\
\text { - Estudos Organizacionais } \\
\text { - Marketing }\end{array}$ & SP & 4 & 4 & \\
\hline
\end{tabular}

${ }^{*}$ Cursos aguardando homologação junto a CAPES (2014).

Fonte: ALFA (2014), ESPM (2014), FACCAMP (2014), FECAP (2014), FEI (2014), FGV/RJ (2014), FGV/SP (2014), FJP (2014), FMU (2014), FNH (2014), FPL (2014), FUCAPE (2014), FUMEC (2014), FURB (2014), IBMEC (2014), IMED (2014), INSPER (2014), PUC/RS (2014), PUC/SP (2014), PUC/PR (2014), PUC/MG (2014), PUC/RJ (2014), UCS (2014), UDESC (2014), UECE (2014), UEL (2014), UEM (2014), UFBA (2014), UFC (2014), UFES (2014), UFF (2014), UFG (2014), UFLA (2014), UFMG (2014), UFMS (2014), UFPB (2014), UFPE (2014), UFPR (2014), UFRGS (2014), UFRJ (2014), UFRN (2014), UFRPE (2014), UFRRJ (2014), UFSC (2014), UFSE (2014), UFSM (2014), UFU (2014), UFV (2014), UMESP (2014), UNA (2014), UNAMA (2014), UNB (2014), UNESA (2014), UNICENTRO (2014), UNIFACS (2014), UNIFEI (2014), UNIFOR (2014), UNIGRANRIO (2014), UNIMEP (2014), UNINOVE (2014), UNIOESTE (2014), UNIP (2014), UNIR (2014), UNISC (2014), UNISINOS (2014), UNISUL (2014), UNIVALI (2014), UNOESC (2014), UNP (2014), UP (2014), UPM (2014), USCS (2014), USP-FEA (2014), USP-FEARP (2014). 